Volume 8. No. 9, September 2020

International Journal of Emerging Trends in Engineering Research

Available Online at http://www.warse.org/IJETER/static/pdf/file/ijeter206892020.pdf

https://doi.org/10.30534/ijeter/2020/206892020

\title{
Design and Implementation of a Low-Cost Printer Head for Embossing Braille Dots on Paper
}

\author{
Jonnatan Arroyo $^{1}$, Ramiro Velázquez ${ }^{1}$, Mehdi Boukallel ${ }^{2}$, Nicola Ivan Giannoccaro ${ }^{3}$, Paolo Visconti ${ }^{3}$ \\ ${ }^{1}$ Universidad Panamericana, Facultad de Ingeniería, Aguascalientes, Mexico, rvelazquez@up.edu.mx \\ ${ }^{2}$ CEA, LIST, Sensorial and Ambient Interfaces Laboratory, Gif-Sur-Yvette CEDEX, France \\ ${ }^{3}$ University of Salento, Department of Innovation Engineering, Lecce, Italy
}

\begin{abstract}
This paper presents the design, implementation, and prototype of a low-cost Braille embossing mechanism. The proposal is a printer head integrating three hammers that, upon actuation, stamp readable dots on the paper. Inspired in the rotary cam-follower mechanism, the hammers are actuated by a single servomotor which rotation determines which hammer strikes the paper. Braille characters can be quickly embossed using the proposed printer head. Affordable and efficient Braille embossers for home use can be envisaged using this new action approach.
\end{abstract}

Key words: Assistive technology, Braille embosser, cam-follower mechanism, mechatronic device, tactile printing.

\section{INTRODUCTION}

Visually impaired people face countless difficulties in their daily lives. This is especially true for activities such as environment understanding, urban mobility, reading, computer access, object finding, among others [1].

In particular, to address the reading and computer access challenges, three solutions have been explored so far with the aim of improving digital text accessibility: screen magnifiers, voice synthesizers, and Braille terminals. Screen magnifiers perform screen magnification for those who still have some degree of remnant vision [2]. Voice synthesizers literally read the text displayed on the computer screen [3], and Braille terminals display the text on the screen in Braille code [4].

Audio books are perhaps the simplest and fastest way to convey text to visual impaired people. Entire print books are recorded while being read out loud. They can be reproduced by standard music players such as desktop component systems or wearable headsets.

Audio books are considered a simple, inexpensive, and non-Braille reading alternative for visually impaired people.
Since they first became available in 1950 , they have been considered a valuable tool for this population. Nowadays, a significant number of titles are available and are accessible via Internet for example, from the NLS [5]. Even though the attractive advantages they offer, two issues have still to be considered [6]:

1) Availability. Not all print books are systematically produced in audible version. Moreover, there is a significant delay for new books that editorials do plan to release in audio version. Having new books in audio form could take a significant amount of time.

2) Audiobooks cannot be considered substitutional to print books. It is true that they fit perfectly the needs of the elderly and non-Braille visually impaired readers. However, as normally sighted prefer to read a printed book instead of listening to it, there is no reason to directly assume otherwise for the visually impaired. Reading heightens the self-esteem, the intellectual activity, and the independence of visually impaired people. Moreover, it increases their literacy and trains their orthography, which is generally quite bad.

Tactile printing is another method for conveying text to the visually impaired. Impact printers can stamp text and graphics (i.e. charts, graphs, mathematical functions, and diagrams) on paper by hitting it with the sufficient force to create a deformation (dot) that can be clearly felt with the fingertips. Their main inconvenient is the cost: Braille embossers or Braille printers roughly go from 2,000 to 80,000 USD [7]. In consequence, they are rarely privately owned. Normally, they can be found and used in some public libraries and special education institutions. The printing cost issue is still to be considered: printing a single page in Braille is five times more expensive than with traditional ink printers. Concerning the industrial fabrication and commercialization of tactile/Braille books, it is even more limited than that of audio books.

The printer head that strikes the paper to stamp the tactile graphics or Braille characters is the main component of the tactile embossers. Commercial embossers usually exploit the 
hammer solenoid technology for implementing their printer heads. Unfortunately, this technology has increased its cost over the years.

With the aim of contributing to the design of small desktop Braille embosser concepts that visually impaired people can own and use at home (Figure 1) and make Braille printing efficient and cost-effective, we introduce in this work a simple low-cost printer head device capable of embossing Braille dots and tactile graphics on paper. This device is based on traditional mechanisms such as the cam-follower and low-cost off-the-shelf actuators such as the servomotor.

The remainder of this paper is structured as follows: Section II introduces the main concepts related to Braille standards and overviews the relevant work performed on Braille character display. Section III details the printer head design and operation principle. Section IV discusses its implementation and use in Braille printers. Finally Section V closes the paper summarizing the main concepts and future work perspectives.

\section{BRAILLE AND BRAILLE DISPLAY}

Thousands of visually impaired people worldwide use Braille in their native languages as an effective way of reading, writing, and learning $[8,9]$. The Braille system, which was created by Louis Braille in 1852, is a system of raised dots, which form letters that can be read with the fingertips. Braille is not a language, rather it is a coding system, which can be used to read and write in many languages such as English, Spanish, French, etc.

In Braille, single text characters are normally represented by six-pin cells. Sixty-four combinations are formed from raising the pins at any of the six positions. In practice, some pin combinations are omitted as they feel the same and are complex to discriminate tactually. Letters, symbols, and words are conveyed to readers from pin combinations. Eight-dot Braille cells can also be found. They are often used to shorten symbols represented by two cells (for example, upper case characters). Figure 2 shows the main specifications of six-dot Braille cells defining the height of dots and the important distances between dots, cells, and lines.

Research concerning Braille character display has mainly focused on implementing refreshable electronic interfaces that are capable of raising and retrieving pins. Piezoelectric [10,11], electromagnetic [12,13], pneumatic [14,15], shape memory alloy (SMA) [16,17], electro active polymers (EAPs) $[18,19]$, and electro rheological (ER) fluids [20,21] technologies have been explored for such purpose. Each technology offers its own advantages and limitations and tradeoffs between the main actuating characteristics (bandwidth, delivered force, cost, integration capacity, and scalability) have to be established for pin implementation.

Braille printing is another way for displaying Braille characters. Unlike tactile electronic interfaces, this method consists on embossing dots permanently on paper.

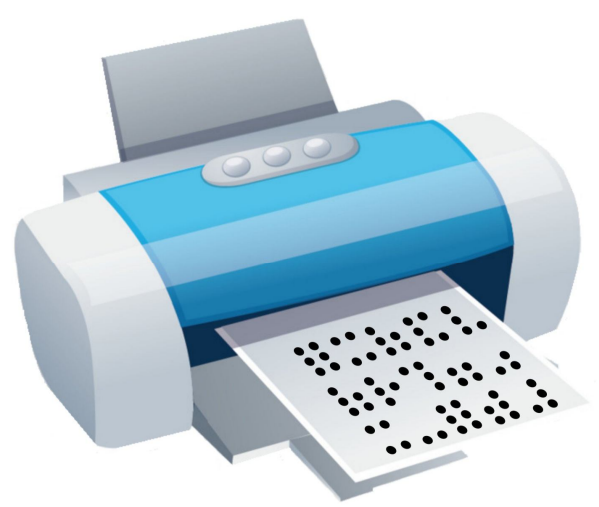

Figure 1: Pictorial representation of a small desktop Braille printer concept.

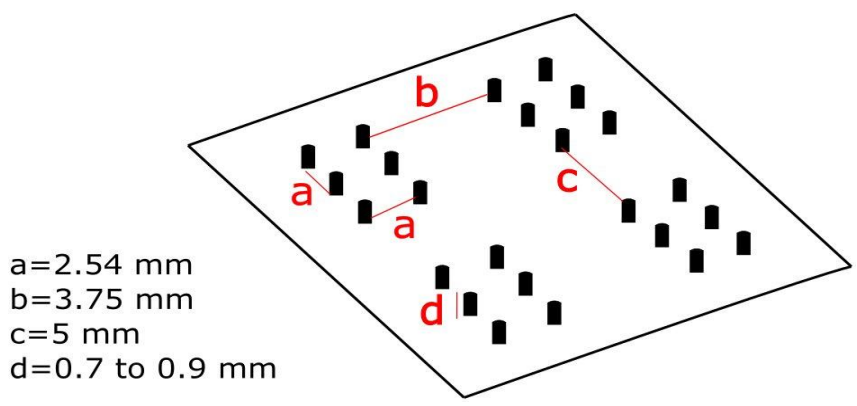

Figure 2: Standard for Braille printed pages.

The most iconic machine for Braille character embossing is the Perkins Brailler. Created by David Abraham in 1951, it is a sort of Braille typewriter with six main keys (one for each Braille dot), and three additional keys for: space, backspace, and line change. Just as in regular typewriters, the keys hit the paper embossing dots on its surface.

Commercial electronic Braille embossers are based on high performance solenoids called hammer solenoids. Prototypes like the EVEREST-D V5 can output up to 140 Braille characters per second using 13 actuators, which amounts to 500 A4 pages per hour [22]. However, this kind of technology is far from being affordable for end users.

Research on Braille printing is sparse: Apurva et al. proposed in [22] a printer head involving three servomotors coupled with gears each actuating two needles. The six dots in a cell can be embossed upon the rotation of the three servomotors. $\mathrm{Li}$ and coworkers introduced in [24] an UV-curing adhesive technique to generate durable Braille dots. By opening a jet 
valve, glue dots are deposited on the paper surface. Kociolek et al. presented in [25] a thermal Braille printing device based on reusable memory shape plastic films. This technique thermally erases dots from sheets already filled with dots.
Duran and colleagues implemented a single hammer mounted in a two-axis platform [26]. When actuated, the hammer stamps a mark on the paper.

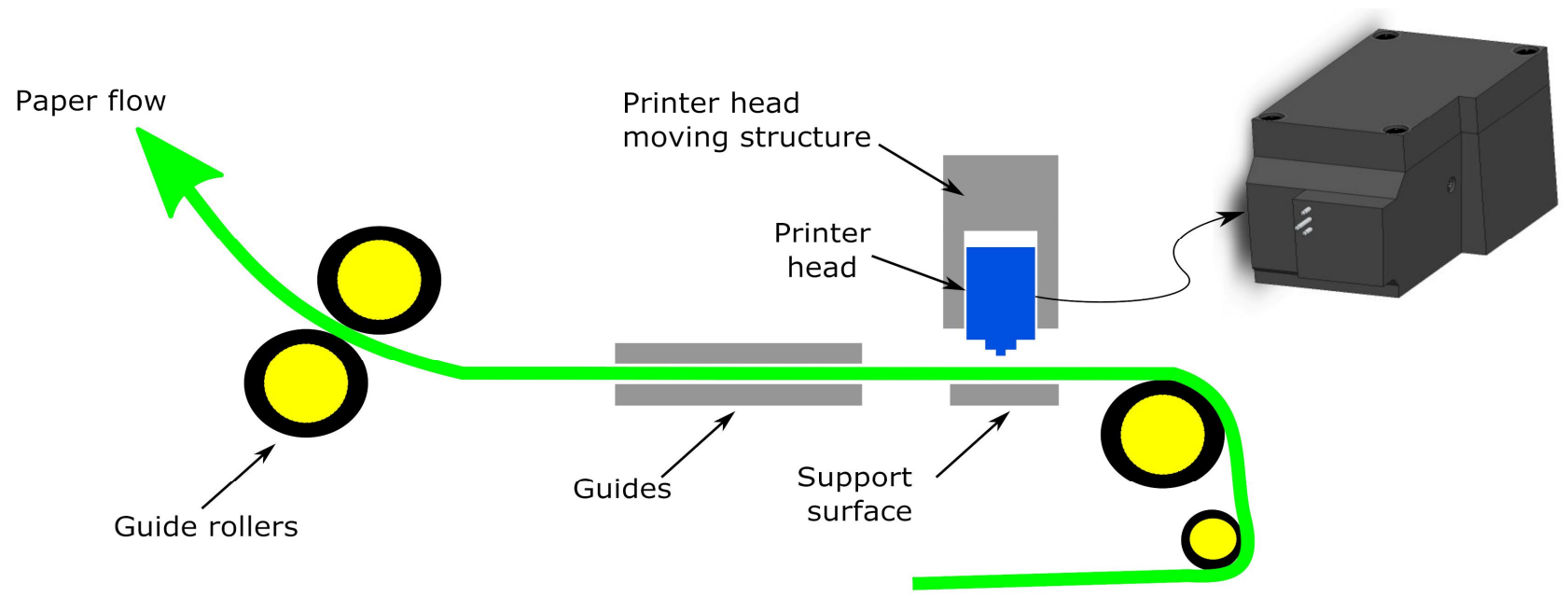

Figure 3: Conceptual design of a simple low-cost Braille embosser. Inset: the three-dot printer head proposal.

This proposal aims to contribute to the Braille printing research area by providing a new and efficient actuation idea for making Braille embossers simpler and thus, truly affordable.

\section{SYSTEM OVERVIEW}

Figure 3 shows the conceptual representation of a Braille embosser. Just as traditional ink printers, paper displacement is to be carried out by one step motor and guide rollers. A second step motor moves horizontally the printer head.

The printer head is detailed in Figure 3 inset. The design targets a device of compact dimensions (73 x $39.5 \times 39 \mathrm{~mm})$ fully complying with Braille standards. Three hammers strike sequentially the paper to stamp Braille dots of $0.8 \mathrm{~mm}$ height. Braille embossing is done column by column, so a Braille character requires three sequences: one hammer strike, then printer head displacement, and finally another hammer strike.

Figure 4 shows the structure and main components of the printer head. Note that rotational motion is transferred from a servomotor to a shaft via a gear train. The shaft encompasses three cam-followers circumferentially arranged at $120^{\circ}$. The rotation of the servomotor determines which cam-follower is actuated. Feedback on the shaft's angular position is ensured by two optical encoders.

Figure 5 describes the printer head's operation while Figure 6 details the actuation sequence of the hammers. To actuate the hammers, the servomotor turns in steps of $120^{\circ}$. For example, to print all three dots on paper, the step motor will turn the full $360^{\circ}$ clockwise $(\mathrm{CW})$. To actuate hammers $\mathrm{P} 1$ and $\mathrm{P} 3$ being in $\mathrm{P} 1$, the motor would only have to turn $120^{\circ}$ counter clockwise (CCW). Note that it is possible to actuate any hammer from any position.

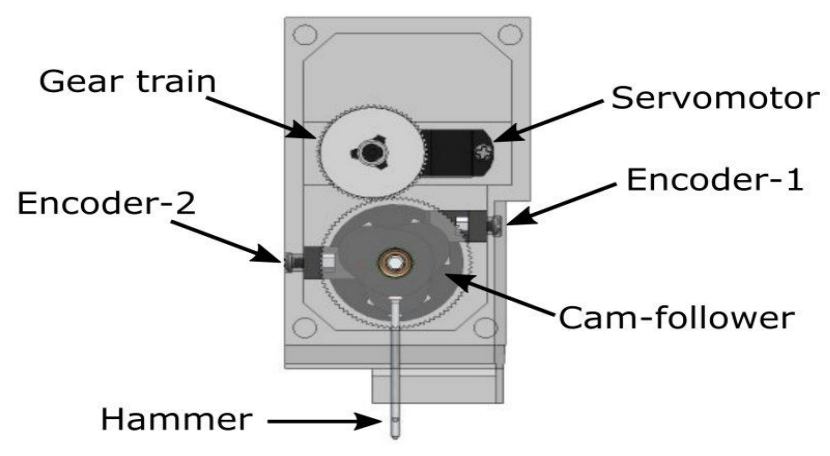

Figure 4: The printer head's main components.

To move the printer head horizontally (i.e. to emboss the next column or cell), no hammer must be actuated (i.e. set down) otherwise there is the risk of breaking the paper or jamming the embosser. For this purpose, the shaft turns $60^{\circ}$ towards the hammer that is next to be actuated to place it in a neutral position. Figure 7 shows the displacement function for the cam-follower mechanisms of the printer head. The first region $\left(0^{\circ}-80^{\circ}\right)$ corresponds to hammer setting (hammer going down to emboss the paper). The hammer marks the paper when the cam is at $80^{\circ}$. The second region $\left(80^{\circ}-160^{\circ}\right)$ corresponds to hammer resetting (hammer rising), and the third one $\left(160^{\circ}-360^{\circ}\right)$ corresponds to hammer in neutral position. 
This actuation approach offers interesting features such as simplicity, compactness, noiseless operation, a single actuator to control, low-cost, and ease of implementation.

\section{IMPLEMENTATION}

For the implementation of the concept, we selected a commercially available low-cost miniature servomotor from
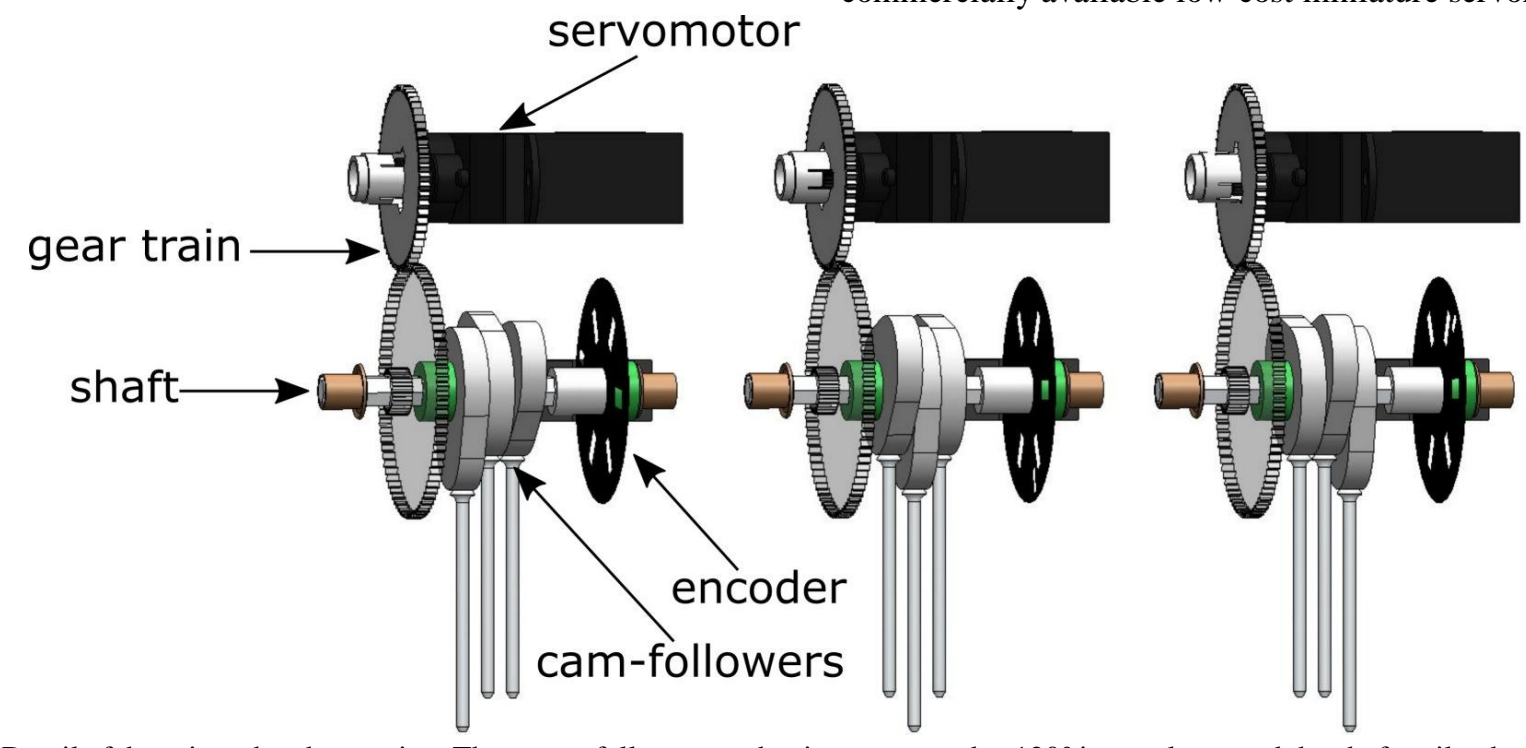

Figure 5: Detail of the printer head operation. Three cam-follower mechanisms arranged at $120^{\circ}$ intervals around the shaft strike the paper. Their actuation is determined by the rotation of the servomotor.

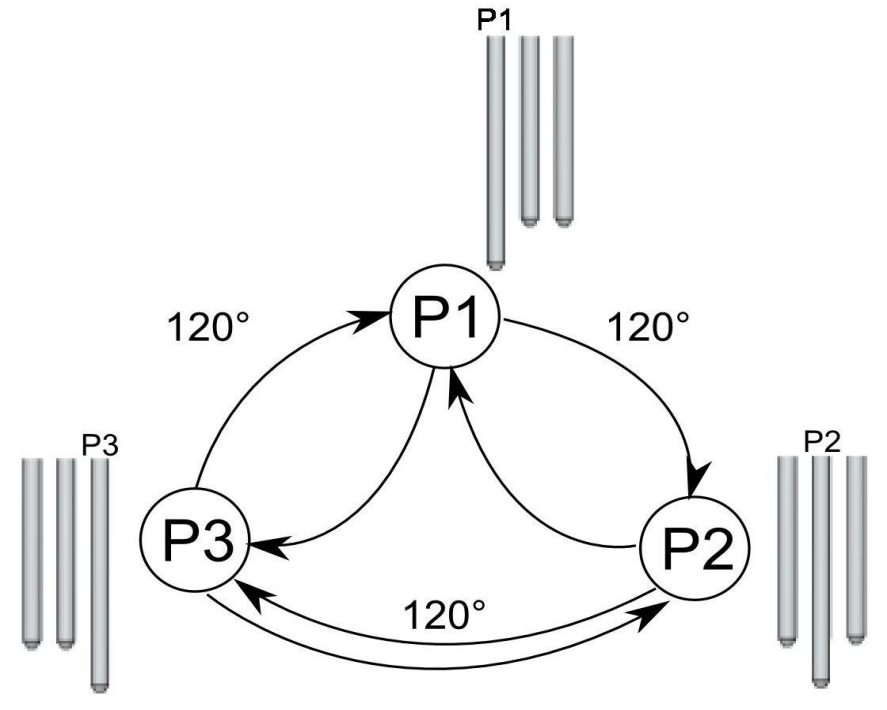

Figure 6: Actuation logic for the hammers: the servomotor turns $\mathrm{CW}$ and $\mathrm{CCW}$ in steps of $120^{\circ}$ to actuate the hammers.

Power HD [27], which provides a $3.5 \mathrm{~kg}-\mathrm{cm}$ torque that ensures that hammers will develop the necessary impact force to emboss the Braille dots on paper. This servomotor offers a speed of $1.5 \mathrm{rad} / \mathrm{s}$, which is appropriate for the application. Its dimensions and mass meet the requirements for the development of a compact printer head.

The gear train and the three cam-follower mechanisms were fast prototyped using thermoplastic material. A second stage envisages its manufacturing using metal. All parts were integrated in an ABS enclosure of compact dimensions just as envisaged conceptually in Figure 3 inset.

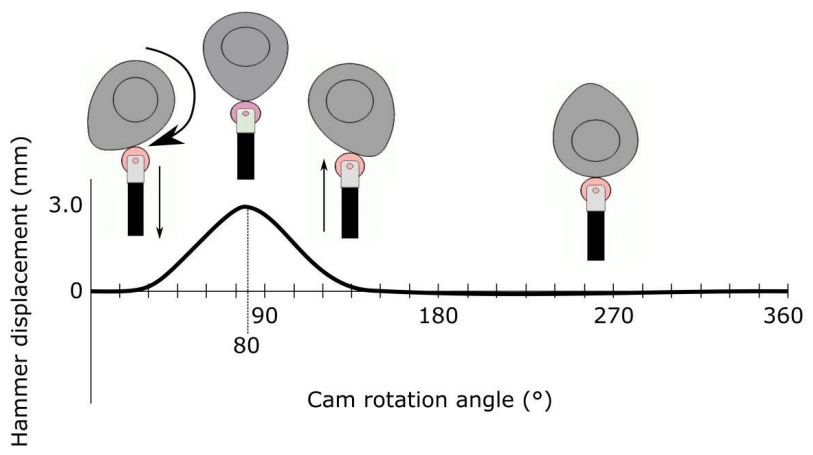

Figure 7: The cam-follower displacement function.

Figure 8(a) shows the elements mounted on the shaft: a gear train and the three cams. As followers (the hammers), wood metal nails were selected together with springs to reset them and ensure their continuous contact with the cams. The wood nails were modified in their tips to obtain a conic shape instead of a cylindrical one and prevent from perforating the paper during impact. In addition, a soft damping material is needed below the printing area (see support surface in Figure 3). Several materials were tested being foamy the one that showed the best results.

Figure 8(b) shows the first prototype of printer head developed. Its final laboratory cost is only 40 USD. The first tests conducted with the prototype have been satisfactory: the hammers emboss correctly Braille dots on bond-type paper commonly used in ink printers. 
The printer head's general control diagram is shown in Figure 9(a). Recall it consists of a servomotor, a gear train, and three cam-follower mechanisms which vertical

movement (y) stamps the paper. Two redundant encoders provide feedback on the shaft's rotation $(\theta 2)$ and allow its comparison with the

\section{Printer head}

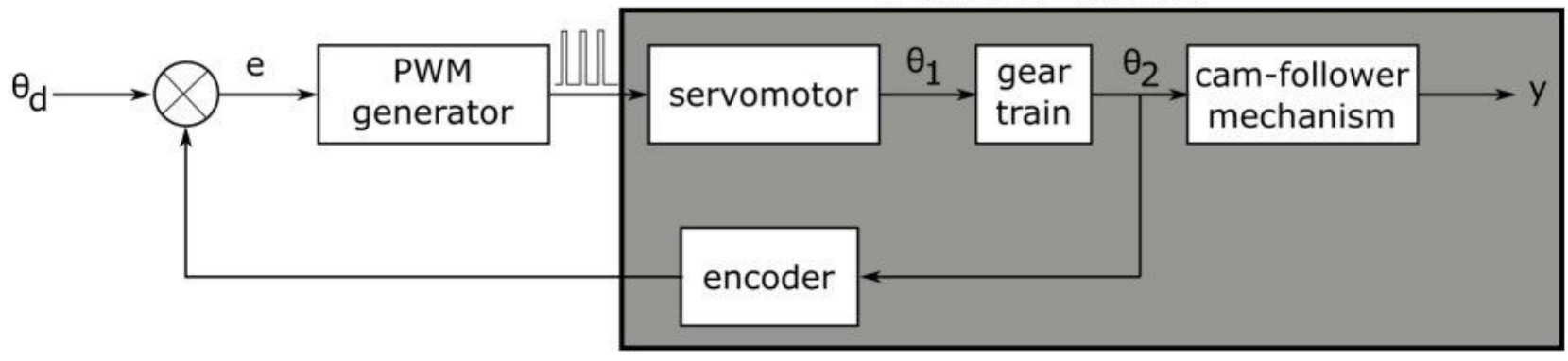

(a)

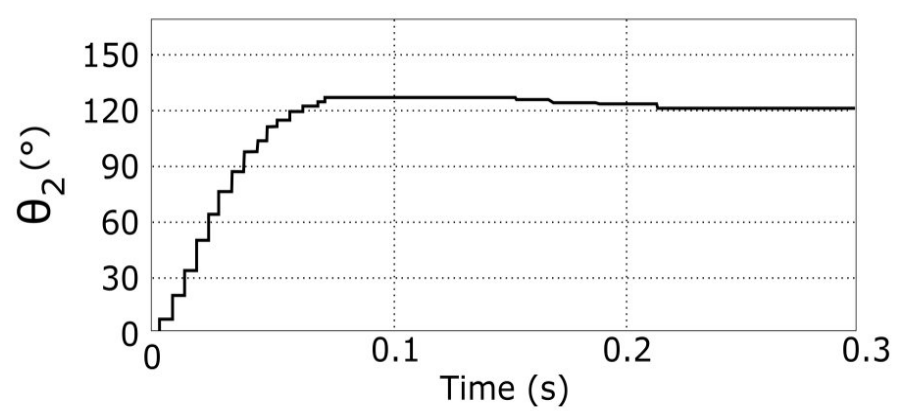

(b)

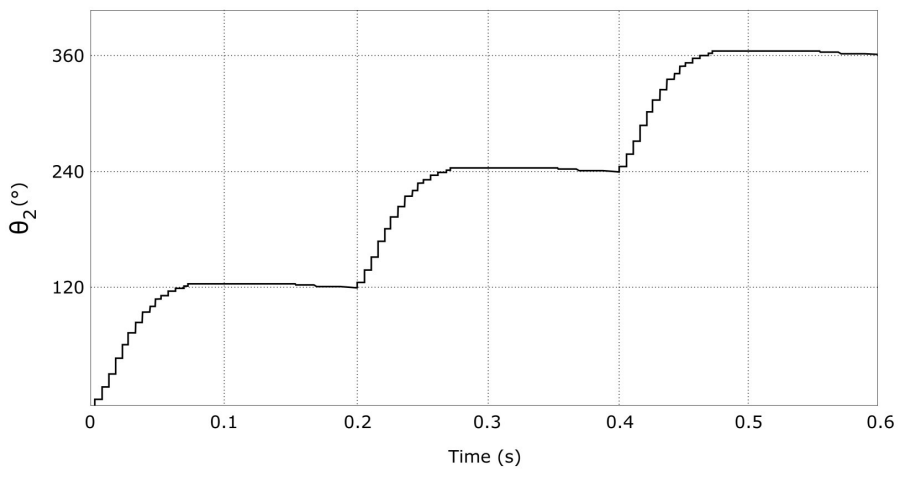

(c)

Figure 9: The printer head's: (a) Control diagram, (b) Response to a $120^{\circ}$ shaft rotation command (one hammer embossing), and (c) Response to a $360^{\circ}$ shaft rotation command (three hammers embossing).

desired command $(\theta \mathrm{d})$. The servomotor uses a PWM input. Experimental results show that the printer head embosses characters at a suitable speed: $0.2 \mathrm{~s} / 120^{\circ}$ (Figure 9(b)). Thus, three-dot columns can be embossed in $0.6 \mathrm{~s}$ (Figure 9(c)).

Figure 10 shows the general schematic diagram of the Braille embosser. Note that the data flow towards the printer head involves two stages: Braille translator and Hardware. The following subsections detail both stages.

\subsection{Braille Translator}

Text to Braille translation can be performed in two grades. Grade 1 Braille is the basic translation in which each printed character is substituted by its Braille equivalent. Grade 2 Braille or contracted Braille is the advanced mode in which words are shortened to fit a single cell. There are 189 contractions of the most commonly used words. Grade 2 Braille follows a complex system of rules and translation can be done properly only by a human [28].

We have developed a computer-based Braille translator tool capable of converting text files into Braille using Grade 1 Braille. Such tool basically consists of a lookup table in which letters are simply associated to their equivalent in Braille (see Figure 11).
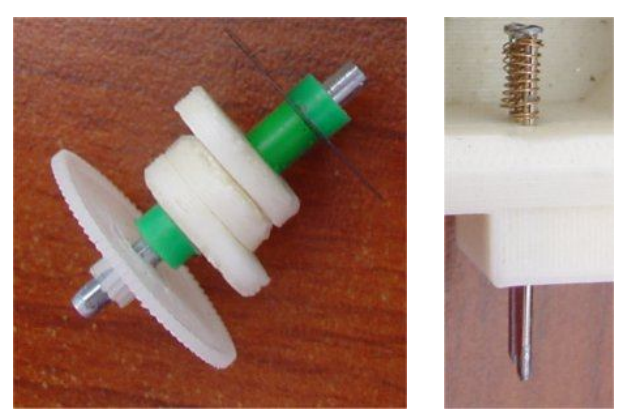

(a)

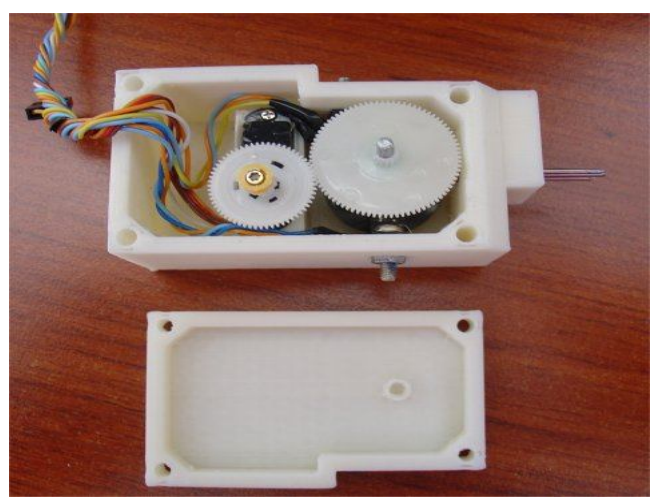

(b)

Figure 8: Printer head: (a) Detail of the elements encompassed on the shaft and (b) prototype. 


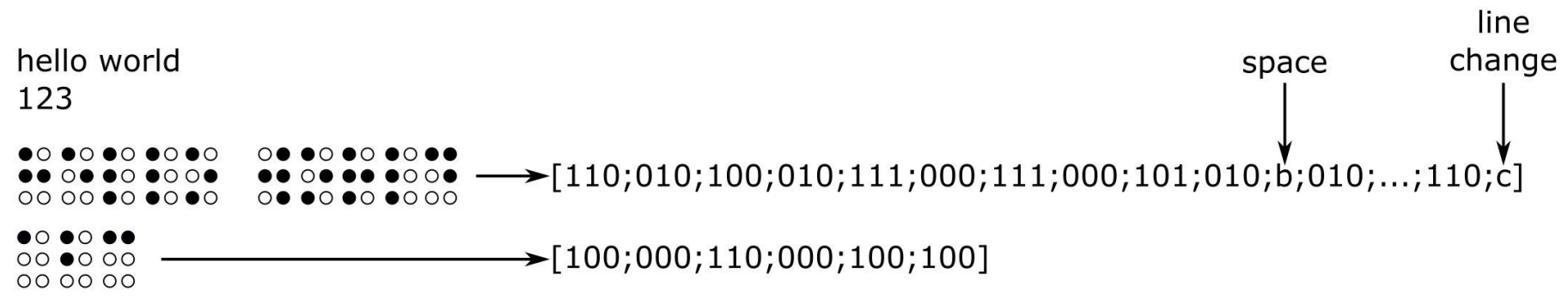

Figure 11: Grade 1 Braille transcription and resulting vectors sent to the hardware module.

Figure 12 shows a snapshot of the graphical user interface (GUI). Developed under a Visual.Net environment, the Braille translator tool was designed to offer users a simple and intuitive translation process:

1) File-upload function: It allows the upload of supported files to be translated into Braille. Currently, the tool supports the most popular file formats such as doc, txt, and pdf.

2) Textbox function: It allows the user to freely type or paste any desired text to be translated.

Experimental measurements of the translator's computing time show that -using a modest resource standard desktop computer (simulating the equipment a visual impaired person would probably have at home) with only $256 \mathrm{MB}$ of RAM memory- a page of 2,000 characters can be translated in $0.8 \mathrm{~s}$. Roughly, a standard 300 page textbook can be fully translated into Braille in $240 \mathrm{~s}$.

This software tool has been used in previous Assistive Technology (AT) projects [4, 29].

Once the Braille transcription has been completed, all characters are encoded as vectors and sent to the hardware module via serial communication. Figure 11 shows how vectors are constructed from the Braille characters. 'One' values indicate dots to be stamped while 'zeros', dots to be skipped. In addition, ' $b$ ' values are used for spaces between words while 'c' values for line change (see correspondence in Figure 2).

\subsection{Hardware}

Figure 13 details the components of the hardware module. Inside the printer, an electronic module encompasses a microcontroller, which processes the Braille vectors generating a buffer to control the printer head's hammers.

Communication between the printer head and the microcontroller is bidirectional because it is necessary to know with accuracy the shaft's position to actuate the camfollower mechanisms.

In addition to receiving the Braille vectors from the software, the microcontroller manages the position data coming from the printer head's encoders and the embosser's sensors. The microcontroller controls the servomotor and the two step-

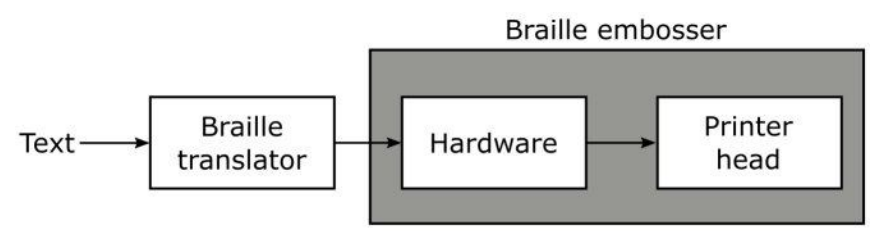

Figure 10: Functional control scheme and data flow.

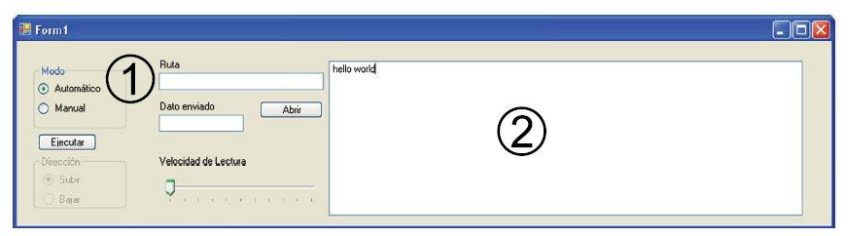

Figure 12: Snapshot of the Braille translator GUI showing its two main functions: 1) file upload and 2) textbox.

motors that actuate the guide rollers and the printer head moving structure (see Figure 3).

Figure 14 shows an example of printing outcome achieved with the prototype presented herein. Braille standard complying dots can be effectively embossed on paper. Our current work seeks to have visually impaired readers assess the printed pages to confirm that Braille characters are tactually discernable and comfortable to the fingertips.

As aforementioned, Braille characters are embossed at speeds of $0.2 \mathrm{~s} / 120^{\circ}$. Letters like ' $y$ ' and ' $q$ ' requiring the highest number of dots (five) can be embossed in $1 \mathrm{~s}$. Most letters of the alphabet are represented by two or three dots requiring an embossing time between 0.5 and $0.7 \mathrm{~s}$, respectively.

Normally, one A4 page can contain around 1,000 characters (25 lines of 40 cells). With our system, printing a regular text page containing most of the letters in the alphabet and spaces between words roughly takes $10 \mathrm{~min}$, which amounts to six A4 pages per hour. Note that this printing speed is suitable for home purposes only.

We are currently working on debugging the microcontroller's code to handle efficiently all input and output data and the daily situations traditional printers face such as paper run out, jams, diverse alerts, etc. 


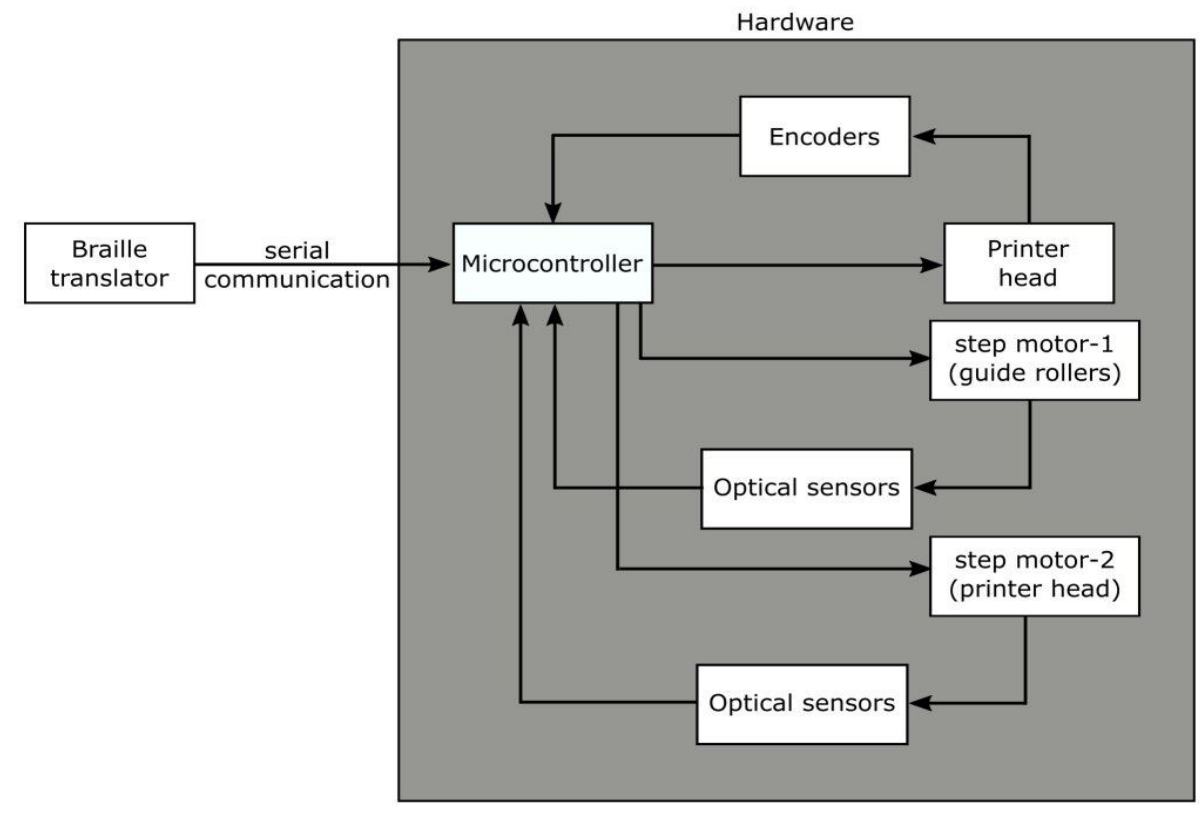

Figure 13: Block diagram of the Braille embosser hardware.

\section{CONCLUSION}

Developing new Assistive Technologies is important for improving the quality of life of visually impaired people. In this paper, we focused our efforts in actuators that can be used for improving digital text document accessibility. In particular, we overviewed the design and implementation of a novel printer head device capable of embossing Braille dots on paper.

Based on the traditional cam-follower mechanism concept and off-the-shelf servomotors, such device consists of three hammers that sequentially strike the paper to stamp Braille characters. The concept is simple, compact, noiseless, low-cost, easy to maintain/repair and is the base for the development of an inexpensive Braille embosser prototype intended for home use.

A Braille embosser prototype was then deployed with the printer head device and a Braille software translator as main components. Experimental results show that texts can be quickly converted into Braille using Grade 1 Braille translation and that Braille characters can be embossed in the range of 0.5 to $1 \mathrm{~s}$.

Future work will focus on expanding the software translating capabilities. In particular, Internet file-formats, such as HTML would allow visually impaired users to directly print web pages in Braille. Other translation approaches such as those based in Neural Networks [30] will be explored to offer more versatility to the prototype. It is also expected to have the translator as a free web service taking into account the quality and appearance concepts for websites described in [31].

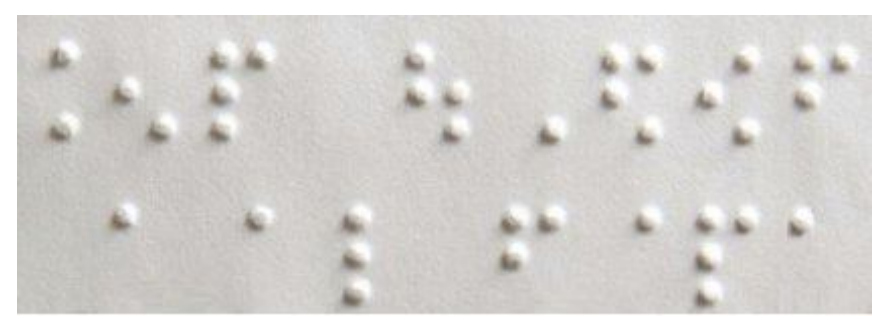

Figure 14: An example of the Braille dots embossed on paper by the printer head prototype.

\section{REFERENCES}

1. E. Pissaloux and R. Velazquez. Mobility of Visually Impaired People: Fundamentals and ICT Assistive Technologies, 1st ed., Springer, 2018.

2. G. Evans and P. Blenkhorn, Screen Readers and Screen Magnifiers, in Assistive Technology for Visually Impaired and Blind People, M. Hersh and M. Johnson (Eds.), Springer, London, pp. 449-495, 2008.

3. M. Gahlawat, A. Malik and P. Bansal, Natural speech synthesizer for blind persons using hybrid approach, Procedia Computer Science, vol. 41, pp. 83-88, 2014.

4. R. Velazquez, H. Hernandez and E. Preza, A portable piezoelectric tactile terminal for Braille readers, Applied Bionics and Biomechanics, vol. 9, no. 1, pp. 45-60, 2012.

5. National Library Service for the Blind and Physically Handicapped. Updated information available at: http://www.loc.gov/nls/ (last access September 2020)

6. R. Velazquez, Wearable Assistive Devices for the Blind, in Wearable and Autonomous Biomedical Devices and Systems for Smart Environment: Issues and 
Jonnatan Arroyo et al., International Journal of Emerging Trends in Engineering Research, 8(9), September 2020, 6183 - 6190

Characterization, A. Lay-Ekuakille, S. Mukhopadhyay (Eds.), LNEE 75, Springer, pp. 331-349, 2010.

7. National Federation of the Blind, Updated information available at: www.nfb.org/ (last access September 2020)

8. S.A. Khidri, S.H. Memon and A. Jameel, Blind aid: A self-learning Braille system for visually impaired, International Journal of Engineering Research and General Science, vol. 2, no. 4, pp. 641-647, 2014.

9. J. Jimenez, J. Olea, J. Torres, I. Alonso, D. Harder and K. Fischer, Biography of Louis Braille and invention of the Braille alphabet, Survey of Ophthalmology, vol. 54, no. 2, pp. 142-149, 2009.

10. I. Summers and C. Chanter, A broadband tactile array on the fingertip, Journal of the Acoustical Society of America, vol. 112, pp. 2118-2126, 2002.

11. H. Hernandez, E. Preza and R. Velazquez, Characterization of a piezoelectric ultrasonic linear motor for Braille displays, in Proc. of Electronics, Robotics and Automotive Mechanics Conference, Cuernavaca, Mexico, 2009, pp. 402-407.

12. J.J. Zarate and H. Shea, Using pot-magnets to enable stable and scalable electromagnetic tactile displays, IEEE Transactions on Haptics, vol. 10, no. 1, pp. 106-112, 2017.

13. M. Benali-Khoudja, M. Hafez and A. Kheddar, VITAL: An electromagnetic integrated tactile display, Displays, vol. 28, no. 3, pp. 133-144, 2007.

14. C. Premarathna, D. Chathuranga and T. Lalitharatne, Fabrication of a soft tactile display based on pneumatic balloon actuators and voice coils: Evaluation of force and vibration sensations, in Proc. of IEEE/SICE International Symposium on System Integration, Taipei, Taiwan, 2017, pp. 763-768.

15. J. Yoo, S. Yun, S.C. Lim, J. Park, K.S. Yun and H.K. Lee, Position controlled pneumatic tactile display for tangential stimulation of a finger pad, Sensors and Actuators A: Physical, vol. 229, pp. 15-22, 2015.

16. R. Velazquez, E. Pissaloux, M. Hafez and J. Szewczyk, Toward low-cost highly portable tactile displays with shape memory alloys, Applied Bionics and Biomechanics, vol. 4, no. 2, pp. 57-70, 2007.

17. D.R. Chaves, I.L. Peixoto, A.C. Lima, M.F. Vieira and C.J. de Araujo, Microactuators of SMA for Braille display system, in Proc. of 2009 IEEE International Workshop on Medical Measurements and Applications, Cetraro, Italy, 2009, pp. 64-68.

18. J. Citerin and A. Kheddar, Electro-Active Polymer Actuators for Tactile Displays, in The Sense of Touch and its Rendering, A. Bicchi, M. Buss, M. Ernst and A. Peer (Eds.), Springer Tracts in Advanced Robotics 45, Springer, pp. 131-154, 2008.

19. M. Matysek, P. Lotz, T. Winterstein and H.F. Schlaak, Dielectric elastomer actuators for tactile displays, in Proc. of World Haptics 2009 - 3rd Joint EuroHaptics Conference and Symposium on Haptic Interfaces for Virtual Environment and Teleoperator Systems, Salt Lake City, USA, 2009, pp. 290-295.
20. Y. Liu, R. Davidson and P. Taylor, Touch sensitive electrorheological fluid based tactile display, Smart Materials and Structures, vol. 14, no. 6, pp. 1563-1568, 2005.

21. M. Goto and K. Takemura, Tactile bump display using electro-rheological fluid, in Proc. of IEEE/RSJ International Conference on Intelligent Robots and Systems, Tokyo, Japan, 2013, pp. 4478-4483.

22. EVEREST-D V5. Index Braille Co. Gammelstad, Sweden. Updated information available at: https://www.indexbraille.com/en-us/braille-embossers/e verest-d-v5?c=EUR (last access September 2020)

23. A. Apurva, P. Thakur and A. Misra, Aiding the visually impaired: Developing an efficient Braille printer, in Proc. of International Conference on Advances in Computing, Communications and Informatics, Udupi, India, 2017, pp. 2128-2133.

24. B. Li, J. Liu, Z. Wang, G. Fang, Graphic printing method for new Braille printer, in Proc. of IEEE Youth Conference on Information, Computing and Telecommunications, Beijing, China, 2010, pp. 150-153.

25. M. Kociolek, B. Wiecek, G. De Mey, F. Steenkeste and C. Muntenau, A Braille printer on reusable thermoplastic sheets, in Proc. of the 1st Joint BMES/EMBS Conference, Atlanta, GA, USA, 1999, pp. 869.

26. I. Duran Encinas, J.A. Sandoval Bringas, A.I. De Casso Verdugo, C. Sandoval Bringas and J.G. Soto Muñoz, Low-cost Braille printer prototype design with OCR technology, in Proc. of International Conference on Inclusive Technologies and Education, San Jose del Cabo, Mexico, 2019, pp. 205-2054.

27. HD-1711MG motor, Power HD, HuiDa RC International Inc., Guangdong, China. Updated information at: http://www.pololu.com/catalog/product/2144 (last access September 2020)

28. Braille Institute of America, Updated information available at: https://www.brailleinstitute.org/ (last access September 2020)

29. R. Velazquez, H. Hernandez and E. Preza, A portable eBook reader for the blind, in Proc. of 2010 Annual International Conference of the IEEE Engineering in Medicine and Biology, Buenos Aires, Argentina, 2010, pp. 2107-2110.

30. M. Bailon, M.A. De Silva, R.J. Lapuz, J.L. Tinio, T.B. $\mathrm{Yu}$ and R.C. Gustilo, Filipino to Chinese Speech-to-speech Translator Using Neural Network with Database System, International Journal of Emerging Trends in Engineering Research, vol. 7, no. 9, pp. 276-282, 2019.

31. B.V. Priya, J.K.R. Sastry, Assessment of Website Quality based on Appearance, International Journal of Emerging Trends in Engineering Research, vol. 7, no. 10, pp. 360-375, 2019. 